\title{
Produção de bioetanol de cana-de-açúcar ${ }^{1}$
}

Rafaela Koglin Bastos ${ }^{2}$, Elisandro Pires Frigo ${ }^{3}$, Emanuelle Zanon $^{4}$, Kenia Gabriela dos Santos ${ }^{5}$, Caroline Thaís Eckert $^{6}$, Alvaro Mari Junior ${ }^{7}$

\footnotetext{
${ }^{1}$ Aceito para publicação no $3^{\circ}$ trimestre de 2013.

2 Tecnóloga em Biocombustíveis pela Universidade Federal do Paraná - UFPR, Setor Palotina/PR, Brasil.

3 Engenheiro Agrícola, Mestre em Engenharia Agrícola, Engenharia de Sistemas Agroindustriais, Doutor em Agronomia, Irrigação e Drenagem, Professor Adjunto do Curso de Agronomia da UFPR, setor Palotina/PR, Brasil.

${ }^{4}$ Tecnóloga em Biocombustíveis pela Universidade Federal do Paraná - UFPR, Setor Palotina/PR, Brasil.

${ }^{5}$ Tecnóloga em Biocombustíveis pela Universidade Federal do Paraná - UFPR, Setor Palotina/PR, Brasil.

${ }^{6}$ Tecnóloga em Biocombustíveis pela Universidade Federal do Paraná - UFPR, Setor Palotina/PR, Brasil.

${ }^{7}$ Engenheiro Ambiental, Mestrando em Energia na Agricultura pela Unioeste, Cascavel/PR, Brasil.
}

Palavras-chave: problemas ambientais, biocombustíveis, escala laboratorial.

\section{Resumo}

O etanol tem sido considerado como um combustível alternativo para diminuir problemas ambientais e energéticos no mundo, em razão da escassez e a alta dos preços dos combustíveis fósseis e da poluição causada por estes. O presente trabalho analisa a produção do etanol em escala laboratorial, desde a obtenção da matéria prima (cana-de-açúcar), moagem, preparo do mosto com controle de parâmetros como o Brix e a temperatura durante o processo de fermentação e posteriormente controle e comparação de dados como as diferentes temperaturas e pressões no processo de destilação do etanol. Os dados obtidos foram expressos em tabelas para facilitar a visualização e discussão dos resultados.

Key-words: environmental problems, biofuels, laboratory scale.

\begin{abstract}
Ethanol has been considered as an alternative fuel to reduce environmental and energy problems in the world, due to the scarcity and high prices of fossil fuels and the pollution caused by them. This paper analyzes the production of ethanol in laboratory scale, from obtaining the raw material (cane sugar), grinding, preparation of wort with control parameters such as Brix and temperature during the fermentation process and then control and
\end{abstract}


comparison data as different temperatures and pressures in the process of distillation of ethanol. Data were expressed in tables for easy viewing and discussion of the results.

\section{Introdução}

A crescente preocupação mundial com o meio ambiente e a diminuição das reservas petrolíferas ao longo das últimas décadas vem gerando pressões sobre o uso dos combustíveis fósseis, considerados os grandes responsáveis pela emissão de gases poluentes na atmosfera. Devido a esses motivos vários países estão buscando alternativas de substituição dessas fontes poluidoras por fontes renováveis. Atualmente, o etanol vem sendo considerado umas das melhores opções dentre as fontes de energia renovável, principalmente nos países desenvolvidos, onde o consumo de combustíveis automotivos é maior. Para a produção do etanol são utilizadas diversas matérias primas ricas em açúcar ou amido, como a cana de açúcar e o milho, que representa atualmente as alternativas mais adotadas nas plantas agroindustriais (SANTOS E SANTOS, 2009).

O mercado consumidor de etanol crescerá ainda mais, tanto nacional quanto mundialmente, em um futuro próximo devido às legislações ambientais que obrigam o uso de biocombustíveis em meio de transportes, ao cumprimento das exigências do protocolo de Kyoto, à mistura deste na gasolina e a disponibilização crescente de automóveis bicombustíveis (PACHECO, 2010).

A fermentação alcoólica é a ação de leveduras sobre açúcares fermentescíveis contidos em uma solução. É um processo biológico no qual a energia fornecida por reações de oxidação parcial pode ser utilizada para o crescimento das leveduras e a oxidação parcial anaeróbia da hexose na produção de álcool e $\mathrm{CO}_{2}$ (LIMA E MARCONDES, 2002).

Uma vez concluída a fermentação alcoólica, o vinho está apto para ser destilado. O princípio da destilação se baseia na diferença entre o ponto de ebulição da água $\left(100{ }^{\circ} \mathrm{C}\right)$ e do álcool $\left(78,4^{\circ} \mathrm{C}\right)$. A mistura água e álcool apresentam ponto de ebulição variável em função do grau alcoólico. Assim, o ponto de ebulição de uma solução hidroalcoólica é intermediário entre aquele da água e do álcool e será tanto mais próximo deste último quanto maior for o grau alcoólico da solução (RIZZON E MENEQUZZO, 2008).

O objetivo desse trabalho foi avaliar a eficiência o processo de fermentação de duas bateladas utilizando leveduras peletizadas. Parâmetros físico-químicos como Brix e temperatura foram avaliados com o intuito de aperfeiçoar as condições experimentais e assim aumentar a eficiência do tratamento. 


\section{Material e métodos}

\section{Unidades de Experimento}

Os experimentos foram desenvolvidos em uma miniusina de produção de bioetanol, situada na Universidade Federal do Paraná (UFPR) - Setor Palotina, na cidade de Palotina, estado do Paraná.

\section{Métodos}

Elaborou-se um fluxograma desde a matéria prima até o álcool produzido. A Figura 1 apresenta o fluxograma do processo de produção de álcool.

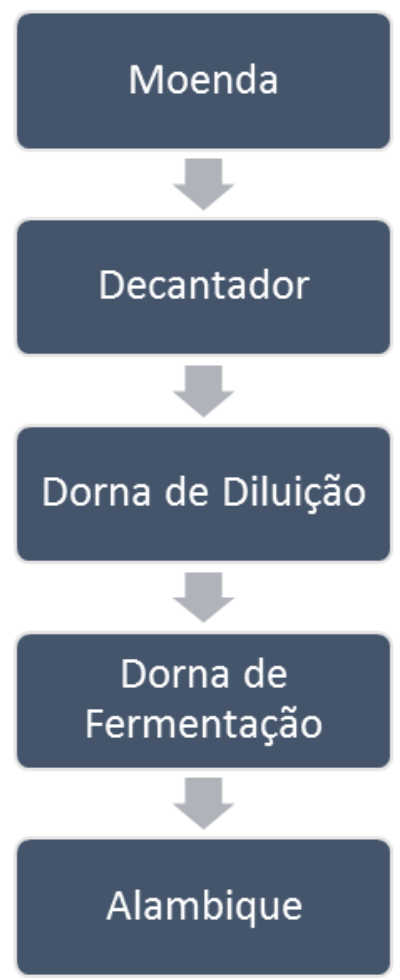

Figura 1: Fluxograma do Processo de Produção de Álcool.

Inicialmente há o aquecimento da caldeira, para no decorrer do processo, ocorrer o fornecimento de vapor visando o alcance da temperatura ideal para o mosto e para o processo de destilação. Porém antes da caldeira ser ligada ocorre um procedimento de drenagem e a minimização do nível desta, isso ocorre para verificar se tem água para o processo e se as bombas estão funcionando.

Para os experimentos utilizou-se cerca de 1 tonelada de cana-de-açúcar. O caldo depois de extraído pelo método de prensagem mecânica, é direcionado ao decantador. A cana 
deve ser limpa, madura, fresca e deverá ser moída num prazo de vinte e quatro horas a trinta e seis horas após o corte (CABRAL et al, 2006). Em seguida, é transferido para a dorna de diluição, calcula-se o Brix e caso este se encontra em um valor muito alto, sendo desfavorável para o processo, deve-se adicionar água até que o Brix seja aceitável.

O mosto presente na dorna de diluição é transferido para a dorna de fermentação, porém antes desse procedimento realiza-se o ajuste na temperatura do mosto em cerca de 32 ${ }^{\circ} \mathrm{C}$. Segundo Stupielo et al (1981) temperaturas inferiores a $30-32{ }^{\circ} \mathrm{C}$ prolongam o tempo de fermentação enquanto temperaturas elevadas inibem o crescimento celular.

Com a temperatura ideal o mosto já presente na dorna de diluição mistura-se com o pé-de-cuba, que já estava contido nessa dorna. O pé-de-cuba é o mosto preparado com cuidados especiais, fazendo com que o fermento tenha melhores condições de desenvolvimento (CABRAL et al, 2006). Adiciona-se 120 gramas de fermento e promove-se a aeração afim de desenvolver o crescimento das leveduras.

O processo de destilação inicia-se quando ao término da fermentação o vinho destina-se para o alambique. Nesta etapa há o controle de análises físico-químicas, como temperatura e teor alcoólico. O teor alcoólico mede-se a cada 5 minutos, para isso utiliza-se um densímetro.

O Brix tem sido um indicador de maturação da cana-de-açúcar bastante utilizado. Este indicador está estreitamente correlacionado com o teor de sacarose da cana, sendo dependente da adubação, controle de pragas e doenças, umidade e grau de compactação do solo, entre outros. O brix possui a vantagem de poder ser medido com refratômetro diretamente no campo e está altamente correlacionado com teor de sacarose (VARELLA et al.). Para início da fermentação o teor do Brix deve ser diluído a aproximadamente 13 graus.

\section{Resultados e discussão}

A fermentação da primeira batelada, ocorrida na aula 1, é denominada de Experimento 1, e a batela que iniciou-se na aula 1 e foi destilada na aula 2 é denominada de Experimento 2.

No Experimento 1 o vinho já estava fermentando por um período de 14 horas e o seu teor de Brix era de 8,3. Para que o vinho fosse destilado e gerasse álcool $94^{\circ}$ seu teor de brix deveria estar em zero, entretanto o mosto foi destilado mesmo estando com o teor de Brix alto. Um dos motivos pelo elevado grau de Brix é decorrente ao fato do envelhecimento da, cana, podendo atingir 22 ou $23^{\circ}$ Brix, isso depende da variedade, época do ano e região (CABRAL, 2006). 
O volume de vinho, é obtido a partir do cálculo do volume da dorna de fermentação, que é calculado pela equação 1 .

$$
V=\frac{\Pi \mathrm{x}(\mathrm{D})^{2} \mathrm{xH}}{4}
$$

Onde:

$\mathrm{V}=$ volume

$\pi=3,14$

$\mathrm{D}=$ diâmetro da dorna

$\mathrm{H}=$ altura do vinho ou pé-de-cuba.

Abaixo o cálculo do volume de vinho do experimento 1, na dorna de fermentação:

$V=\frac{3,14 x(100)^{2} \times 58}{4}=455300 \mathrm{~cm}^{3}$

Convertendo $\mathrm{cm}^{3} \mathrm{em} \quad$ litros:

$V(L)=\frac{455300}{1000}=455,3 \mathrm{~L}$

De acordo com o cálculo de volume da dorna, foi obtido que o volume do vinho a ser destilado era 455,3 L. Transferiu-se então o mosto fermentado da dorna de fermentação para o alambique, esta transferência foi realizada com o auxílio de uma bomba, tomando-se cuidado com o volume adicionado pois a capacidade do alambique é de 400 L. Segundo Rizzon e Meneguzzo (2008), o aquecimento do alambique para a destilação é realizada a fogo direto ou por injeção de vapor dentro da panela através de uma serpentina perfurada., e trabalhando-se com o vapor o controle do aquecimento torna-se mais fácil. A fonte de aquecimento quando não controlada gera dificulta o processo de destilação.

$\mathrm{Na}$ dorna de fermentação, foi retido o pé-de-cuba para ser utilizado na fermentação do Experimento 2.

Para calcular o volume do pé-de-cuba utilizamos o volume da dorna com a respectiva altura do pé-de-cuba na equação 1 .

$V=\frac{3,14 x(100)^{2} \times 19}{4}=149150 \mathrm{~cm}^{3}$ 
O volume de pé-de-cuba retido é de 149,15 L.

A válvula de refluxo, ficou com $1 / 4$ de abertura, permitindo a passagem de álcool que condensou-se na coluna de destilação. O álcool condensado foi coletado com uma proveta de $230 \mathrm{ml}$ para que fosse feita a medição do volume alcoólico com um densímetro.

A destilação é um processo de separação pelo qual um líquido, por efeito de aquecimento, passa para a fase gasosa e, em seguida, volta ao estado líquido por meio de resfriamento. Quando se trata de uma única substância o líquido destilado tem a mesma composição do líquido original. Quando se trata da ocorrência conjunta de líquidos imiscíveis, o destilado encerra o líquido que tem ponto de ebulição mais baixo. No caso de líquidos perfeitamente miscíveis, os vapores destilados se compõem de uma mistura de vapores dos dois, com predominância daquele de menor volatilidade (GRUPO TCHÊ QUÍMICA). A mistura a ser destilada é a mistura água/álcool, que possuí pontos de ebulição diferentes, temperatura de ebulição da água é de $100{ }^{\circ} \mathrm{C}$, enquanto a temperatura de ebulição do etanol (álcool) é de $78,4{ }^{\circ} \mathrm{C}$. Abaixo a Figura 2 apresenta o gráfico da curva de tempo por temperatura da temperatura do destilador.

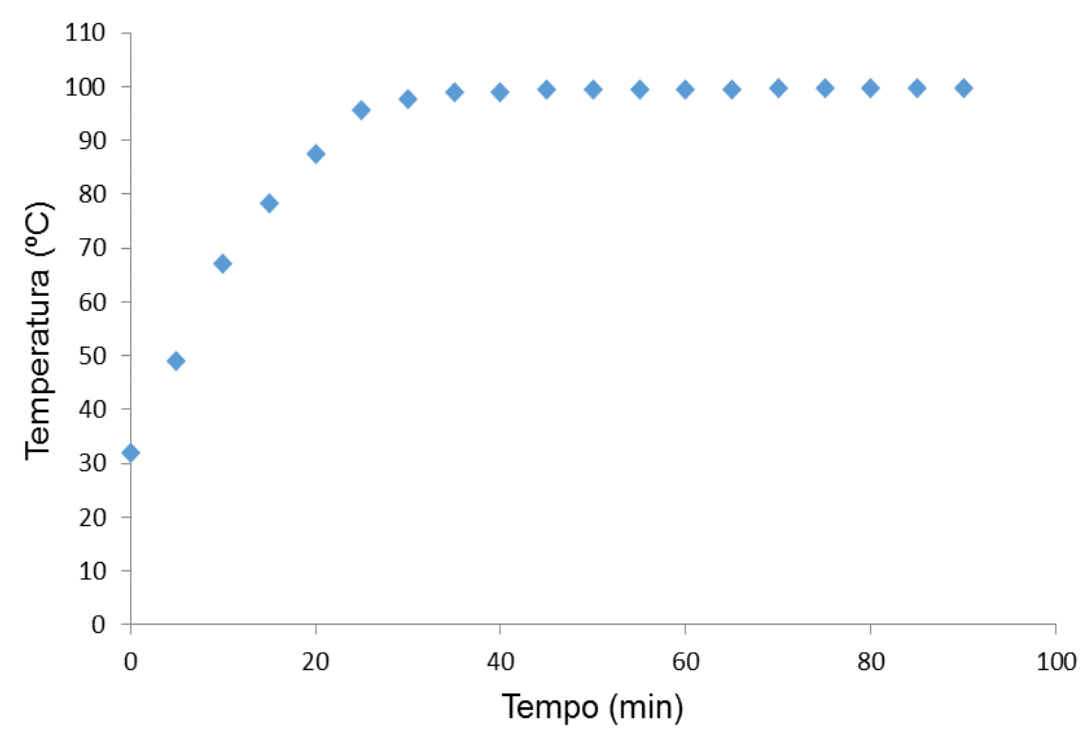

Figura 2: Gráfico de tempo por temperatura do destilador.

Na figura 2 observa-se que a temperatura do destilador inicia-se a $32{ }^{\circ} \mathrm{C}$, que é a temperatura em que o vinho estava na dorna de fermentação, e cresce até $99,7{ }^{\circ} \mathrm{C}$. Até o tempo 25 min observa-se que houve uma rampa de crescimento na temperatura, e após o tempo 25 min no qual a temperatura era $95,7^{\circ} \mathrm{C}$ a temperatura estabilizou-se variando apenas $4{ }^{\circ} \mathrm{C}$ até a temperatura de $99,7^{\circ} \mathrm{C}$. Levando-se em consideração que a temperatura de ebulição do etanol é de $78,4^{\circ} \mathrm{C}$, observa-se que ele começou a evaporar a partir do tempo $15 \mathrm{~min}$. 
O deflagmador e o destilador auxiliam o processo de destilação juntamente com o alambique (RIZZON E MENEGUZZO, 2012).

Através da figura 3 observa-se o gráfico das temperaturas do destilador, de deflagmador e do alambique.

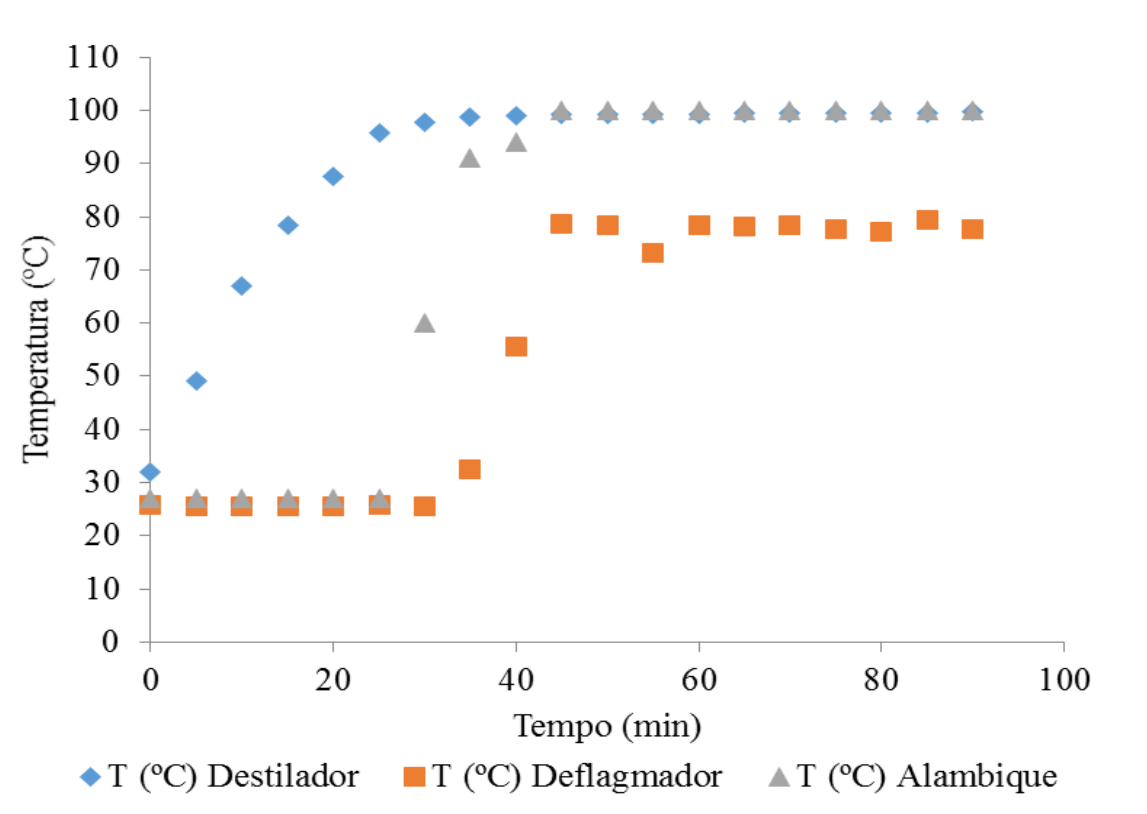

\section{Figura 3: Gráfico do tempo pela temperatura do destilador do deflagmador e do alambique pelo tempo.}

A temperatura do deflagmador permanceu constante até o tempo 25 minutos, porém variou até o tempo 55 minutos, em seguida permanceu constante até o fim da destilação. $\mathrm{O}$ deflagmador permite uma obtenção de uma graduação alcoólica mais elevada (RIZZON E MENEGUZZO, 2006).

A temperatura de destilação permaneceu constantes apartir do tempo de 25 minutos. A destilação a uma pressão constante resulta em uma temperatura constante durante a destilação desde que seja favorecido calor suficiente para assegurar uma velocidade de destilação uniforme e se evite sobreaquecimento. Contudo essas condições ideais podem não ocorrer pois a presença de correntes de ar acabam provocando a condensação do vapor (TÉCNICAS LABORATORAIS DE QUÍMICA).

A leitura do teor alcoólico tem tempo real permitirá fazer a correção em tempo real, evitando oscilações no teor alcoólico do produto final. $\mathrm{O}$ aumento do teor alcoólico diminui gradativamente a volatilidade relativa do etanol (JUNIOR, 2010). Na figura 4 observa-se a graduação alcoólica ao longo da destilação do primeiro experimento. 


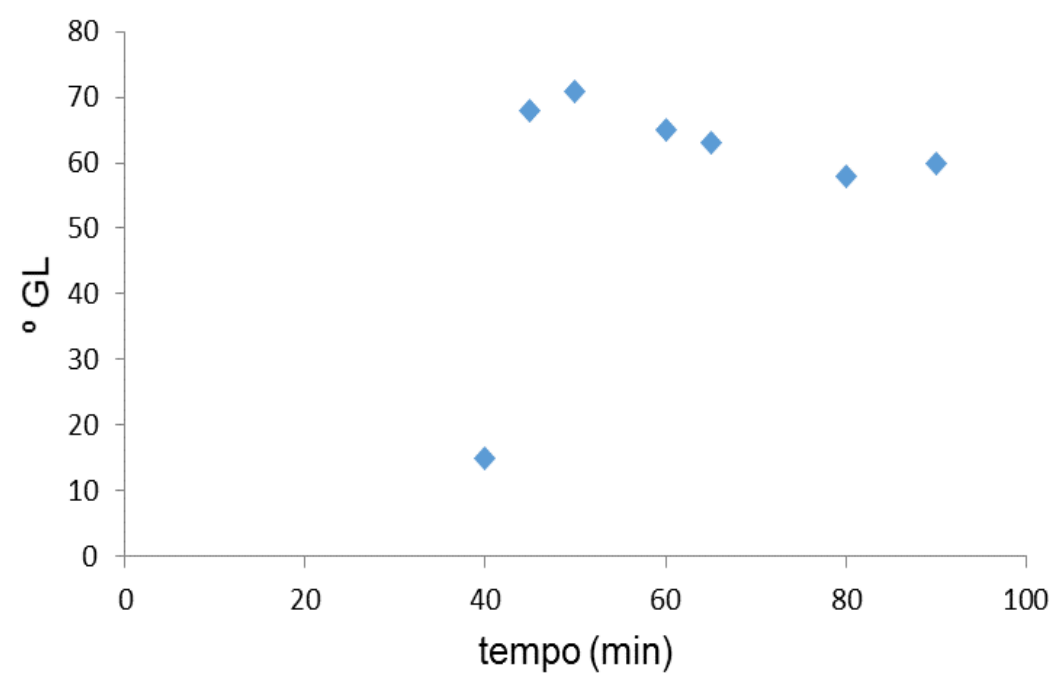

Figura 4: Gráfico do tempo pela graduação alcoólica.

Através da figura 4 concluí-se que a graduação alcoólica começou a ser medida a partir do tempo 40 minutos, pois antes disso não estava sendo destilado nenhum componente. Concluí-se também que ao final da destilação a graduação alcoólica era $60{ }^{\circ} \mathrm{GL}$, caracterizando esse processo inviável, pois não promoveu-se a geração de álcool. A graduação alcoolica esperada para o final da fermentação é de $95^{\circ} \mathrm{GL}$ a $97,2^{\circ} \mathrm{GL}$, pois acima deste valor a mistura álcool/água forma uma mistura azeotrópia, tornando-se inviável economicamente a obtenção de álcool acima de $98{ }^{\circ} \mathrm{GL}$ (RASOVISKY, 1979). O alto teor sólidos fermentáveis eleva a velocidade de fermentação, provacando perdas da atividade de transporte de sólidos produzindo menos álcool (SOUZA, 2009).

Através da figura 5 é possível observar a relação entre a temperatura do condensador e o tempo de experimento. 


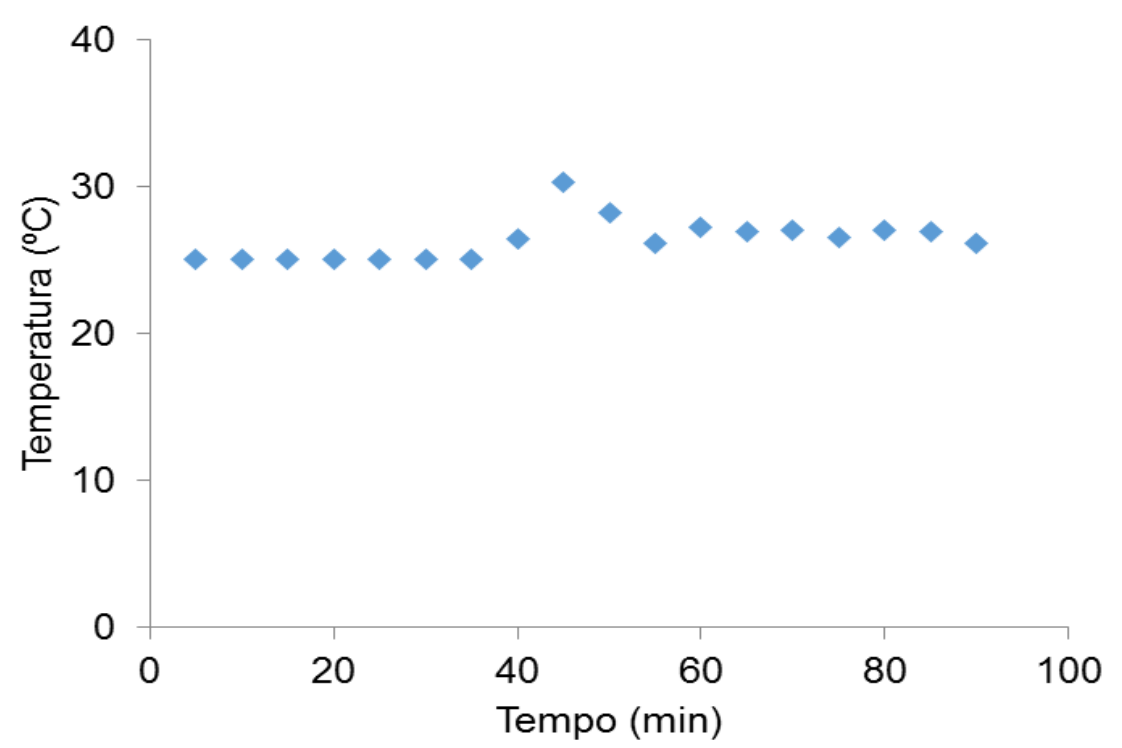

Figura 5: Gráfico do tempo em função da temperatura do condensador.

De acordo com a figura 6, pode-se concluir que a temperatura do condensador permaneceu relativamente constante, e a variação que teve em 45 minutos, deu-se em detrimento de alguma pequena variação de controle mecânico da pressão.

Inicialmente para a realização do Experimento 2 foi moído 1 tonelada de cana-deaçúcar, o caldo da cana-de-açúcar passou por um decantador para ser retiradas as impurezas, e foi transferido para a dorna de diluição, lá foi medido o Brix, o mesmo estava em $16^{\circ}$ Brix. De acordo com Pacheco a fermentação deve iniciar-se com o teor de Brix em torno de $12{ }^{\circ}$ Brix. Por este motivo o caldo de cana foi diluído até o Brix chegar no valor de $13,2{ }^{\circ} \mathrm{C}$.

A temperatura é uma das condições ambientais que mais afetam a atividade de microrganismos, promovendo alterações no crescimento, metabolismo, capacidade fermentativa e viabilidade celular em leveduras (BATISTA, 2001).

O vinho com $13,2^{\circ}$ Brix e $32{ }^{\circ} \mathrm{C}$, foi transferido par a dorna de fermentação, onde entrou em contato com o pé-de-cuba já existente. Entretanto foi adicionado $125 \mathrm{~g}$ de leveduras peletizadas para auxiliar na fermentação. $O$ vinho ficou no estágio de fermentação por um período de 64 horas e o seu teor de Brix reduziu-se para $4,4{ }^{\circ}$ Brix. Para que o vinho fosse destilado e gerasse álcool $94^{\circ}$ seu teor de Brix deveria estar em zero, entretanto como foi adicionado leveduras em excesso o Brix não chegou a zero, pios a alta quantidade de leveduras inibem a fermentação, entretanto, segundo Pacheco (2010) durante a fermentação as leveduras podem estar expostas a vários fatores estressantes como por exemplo os altos teores alcoólicos, como foi adicionado leveduras em excesso o Brix não chegou a zero, pios a alta quantidade de leveduras inibem a fermentação pois produzirem grande quantidade de álcool. 
O volume de vinho, é obtido a partir do cálculo do volume da dorna de fermentação, que é calculado pela equação 1 .

$$
V=\frac{\pi \cdot(\mathrm{D})^{2} \cdot \mathrm{H}}{4}
$$

Onde:

$\mathrm{V}=$ volume

$\pi=3,14$

$\mathrm{D}=$ diâmetro da dorna

$\mathrm{H}=$ altura do vinho ou pé-de-cuba.

Abaixo o cálculo do volume de vinho do experimento 1, na dorna de fermentação:

Dorna de Fermentação

$V=\frac{3,14 x(100)^{2} \times 60}{4}=471000 \mathrm{~cm}^{3}$

Convertendo $\mathrm{cm}^{3}$ em litros:

$471000: 1000=471 \mathrm{~L}$

De acordo com o cálculo de volume da dorna, foi obtido que o volume do vinho a ser destilado era 471 L. Transferiu-se então o mosto fermentado da dorna de fermentação para o alambique, esta transferência foi realizada com o auxílio de uma bomba, tomando-se cuidado com o volume adicionado pois a capacidade do alambique é de 400L.

Na dorna de fermentação, foi retido o pé-de-cuba para ser utilizado na fermentação do Experimento 2.

Para calcular o volume do pé-de-cuba utilizamos o volume da dorna com a respectiva altura do pé-de-cuba na equação 1 .

$V=\frac{3,14 x(100)^{2} \times 19}{4}=149150 \mathrm{~cm}^{3}$

O volume de pé-de-cuba retido é de 149,15 L.

A válvula de refluxo, ficou fechada, e foi aberta totalmente a cada 5 minutos para que fosse coletada uma da coluna de destilação, para calcular a graduação alcoólica. O álcool condensado foi coletado com uma proveta de $230 \mathrm{ml}$ para que fosse feita a medição do volume alcoólico com um densimetro. 
A mistura a ser destilada é a mistura água/álcool, que possuí pontos de ebulição diferentes, temperatura de ebulição da água é de $100{ }^{\circ} \mathrm{C}$, enquanto a temperatura de ebulição do etanol (álcool) é de $78,4{ }^{\circ} \mathrm{C}$. Abaixo a Figura 6 apresenta o gráfico da curva de tempo por temperatura da temperatura do destilador do experimento 2.

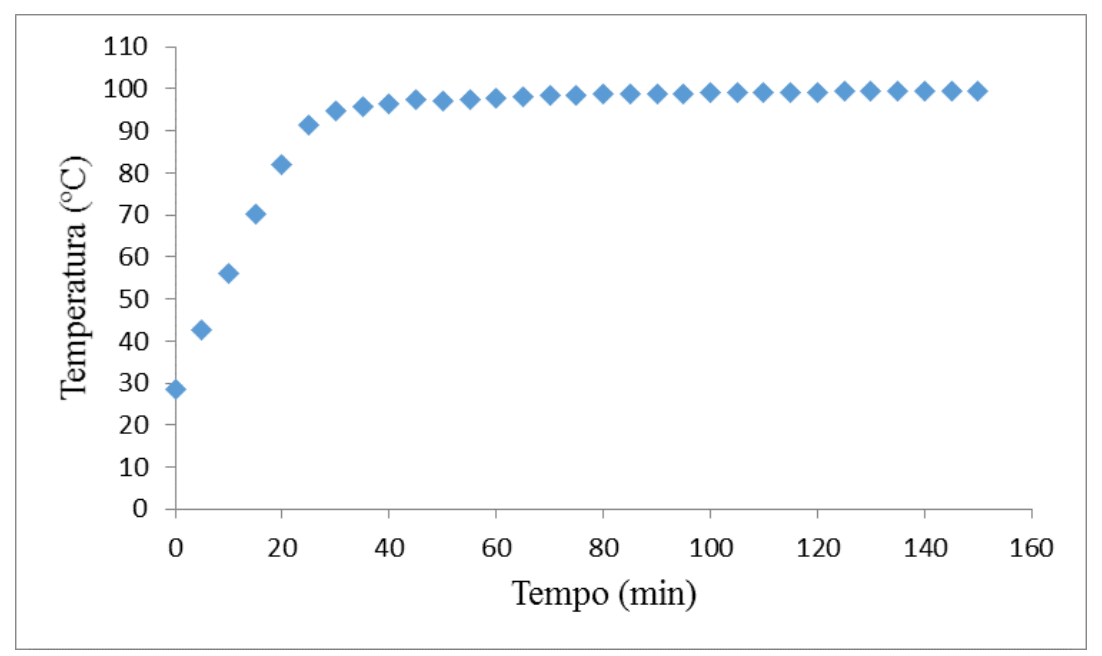

Figura 6: Gráfico do tempo (min) em função da temperatura do destilador.

No gráfico da figura 6 observa-se que houve uma rampa de crescimento do tempo zero ao tempo 20 minutos, na qual a temperatura saltou de $28,5{ }^{\circ} \mathrm{C}$ para $82,0{ }^{\circ} \mathrm{C}$ respectivamente. Como a temperatura de ebulição do álcool $78,4^{\circ} \mathrm{C}$, conclui-se que o mesmo começou a evaporar no entre o tempo de 15 e 20 minutos. A partir do tempo 40 minutos, houve uma pequena estabilização da temperatura, pois a mesma variou apenas $3,1{ }^{\circ} \mathrm{C}$ até o final da destilação.

A figura 7 apresenta o gráfico dão tempo pela temperatura do destilador, do deflagmador e do alambique. 


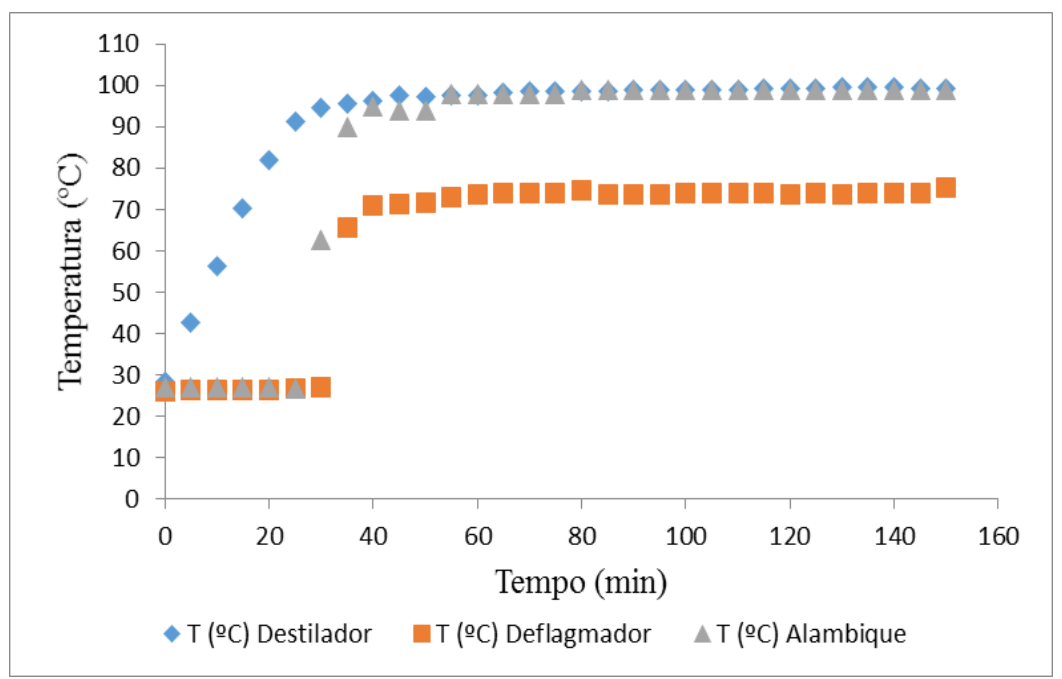

Figura 7: Gráfico do tempo pela temperatura do destilador, do deflagmador e do alambique.

A partir da figura 7, podemos observar que, A temperatura do deflagmador permanceu constante, variando menos de $1{ }^{\circ} \mathrm{C}$, até o tempo 30 minutos. A sua rampa de crescimento se deu do tempo 30 minutos, ao tempo 40 minutos, onde variou $44,1^{\circ} \mathrm{C}$. A partir do tempo 40 minutos houve uma variação de apenas $4,2{ }^{\circ} \mathrm{C}$ até o final do processo, o que podemos chamar de período de temperatura constante por conta da pouca variação.

A temperatura de destilação permaneceu relativamente constante apartir do tempo de 30 minutos, pois até o final da destilação ela variou apenas $4,7^{\circ} \mathrm{C}$. Sua rampa de crescimento esta presente do tempo zero ao tempo 25 minutos, onde ocorreu uma variação de $62,9^{\circ} \mathrm{C}$.

Quanto a temperatura do alambique, podemos observar que inicialmente ela mantémse contante do tempo zero ao tempo 25 minutos. Logo após, tem-se um salto de $62,8{ }^{\circ} \mathrm{C}$ do tempo 25 a 35 minutos, e apartir do tempo 35 minutos a temperatura varia apenas $9{ }^{\circ} \mathrm{C}$ até o final do processo.

Logo que a temperatura se eleva os elementos mais voláteis da mistura, que evaporam a baixas temperaturas, são os primeiros a evaporar. Este fato permitir-nos-á isolar os diferentes componentes da mistura, uma vez que estes tornar-se-ão predominantes a temperaturas diferentes. Se efectuarmos uma leitura da temperatura poderemos verificar o componente predominante naquela determinada altura. Os vapores acumulados no capacete do alambique deslocam-se para o recipiente de condensação através de um tubo de conexão ou de um pescoço de cisne. Caso se trate de um alambique tradicional o pescoço de cisne conduz a uma serpentina localizada no condensador, o qual se encontra cheio com água fria. Logo que os vapores entram em contato com a superfície fria da serpentina condensam, 
regressando ao seu estado líquido, descendo ao longo da serpentina, sendo colhido num recipiente lentamente. Este processo deve ser cuidadosamente supervisionado permitindo-lhe, assim, saber exactamente o que se encontra a colher em qualquer etapa da destilação, uma vez que não desejamos colher quaisquer substâncias nocivas. (COPPERCRAFTS)

No experimento 2, o processo de fermentação completou-se e foi possível obter álcool $94^{\circ}$ GL. Na figura 8, podemos observar o gráfico do tempo pela graduação alcoólica.

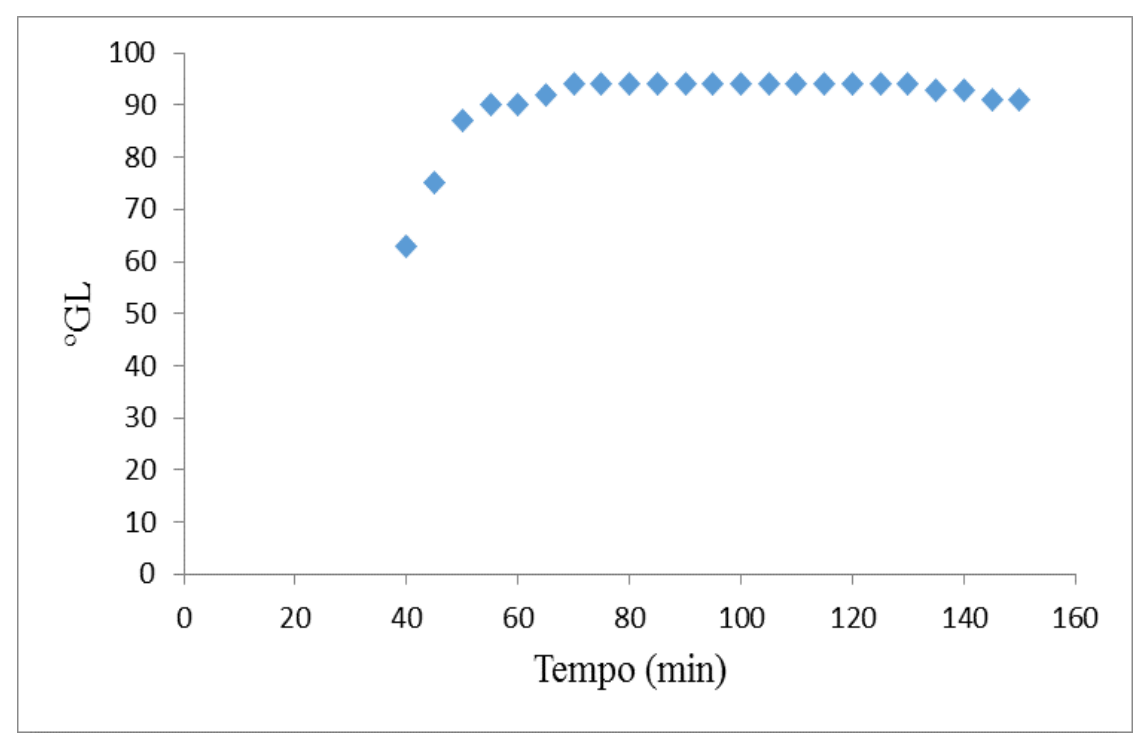

Figura 8: Gráfico de tempo por graduação alcoólica.

O álcool só é produzido quando a graduação alcoólica do destilado chega a $94{ }^{\circ} \mathrm{GL}$. $\mathrm{Na}$ figura acima observamos que o destilador começou a produzir mistura água/álcool a partir do tempo 40 minutos, onde a primeira graduação alcoólica foi medida a com $63{ }^{\circ} \mathrm{GL}$. Observando o gráfico também concluí-se que a partir do tempo 70 minutos começou a ser produzido álcool $94^{\circ} \mathrm{GL}$, ou seja, a destilação iniciou-se no tempo 70 minutos e estabilizou-se até o tempo 130 minutos com $94{ }^{\circ} \mathrm{GL}$. No tempo de $135^{\circ} \mathrm{GL}$ a destilação baixou o ${ }^{\circ} \mathrm{GL}$ para $93^{\circ}$ e passou para o período estacionário no tempo 150 minutos, onde a graduação alcoólica obtida foi $91^{\circ}$. A figura 9 apresenta o gráfico da graduação alcoólica dividido em três fases, fase A, fase B e fase $C$. 


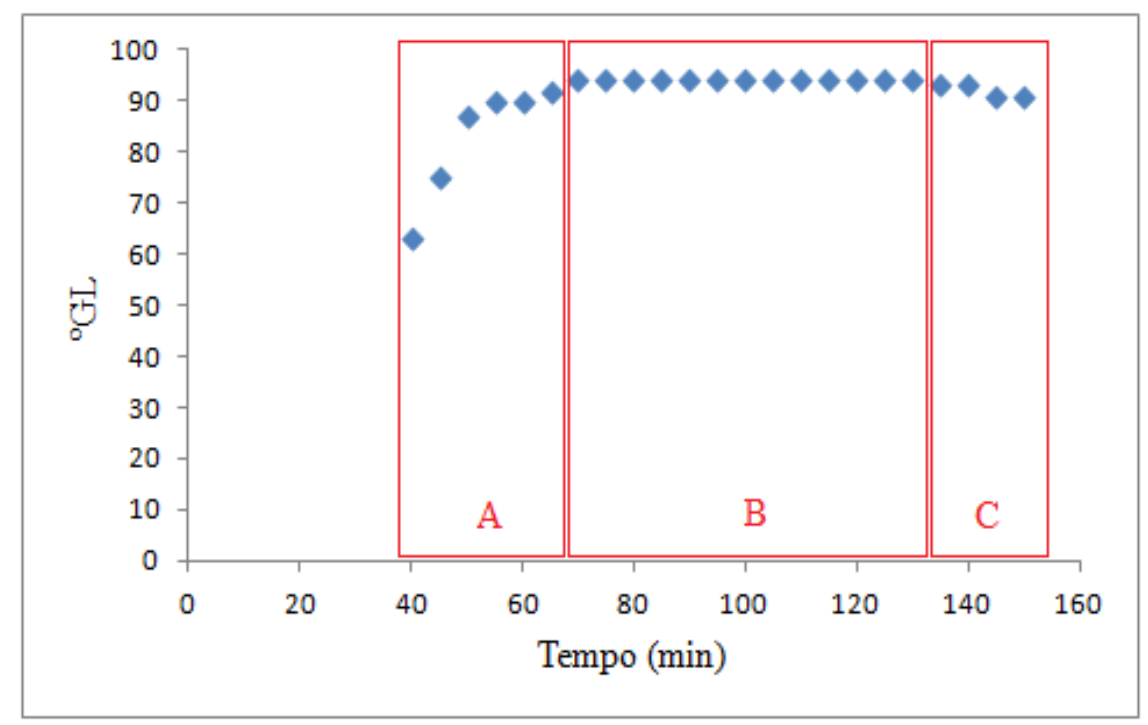

Figura 9: Gráfico da graduação alcoólica dividido por fases.

A fase A representada no gráfico é o que chamamos de período de start up, que é quando é liberado vapor para esquentar o vinho até produzir álcool $94^{\circ} \mathrm{GL}$, logo após vêm a fase $\mathrm{B}$, onde a graduação alcoólica entra em um estado estacionário, ou seja, onde ela produz apenas álcool $94{ }^{\circ} \mathrm{GL}$. Após a fase estacionária, vem a fase de declínio, que é onde a graduação alcoólica baixa para $93{ }^{\circ} \mathrm{GL}$, e não compensa manter o processo depois deste tempo por conta que não está mais sendo produzido álcool. À fase A é representada do tempo 40 a 65 minutos, a fase $\mathrm{B}$ do tempo 70 a 130 minutos e a fase $\mathrm{C}$ do tempo 135 e 150 minutos. Durante todo o processo, tanto do experimento 1 como do experimento 2 a pressão permaneceu constante em 0,5 bar.

Não foi possível calcular o rendimento da fermentação, pois na primeira experimento não ocorreu a produção de álcool $94{ }^{\circ} \mathrm{GL}$, devido a má qualidade das leveduras. No segundo experimento não se obteve o teor alcoolico do vinho, pois o densimetro do laboratório é especifico para água e álcool.

\section{Vazão de destilado}

Numa vazão constante mediu-se o tempo gasto para preencher uma proveta de 250 $\mathrm{mL}$, quando se produz álcool $94^{\circ} \mathrm{GL}$. A determinação da vazão do destilado é obtida através da equação 2.

$$
V=\frac{v(L)}{t(h)}
$$


Coletou-se $250 \mathrm{~mL}$ de álcool destilado em um tempo de 6 minutos e 13 segundos $\log 0$

$V=\frac{0,25(L)}{0,1036(h)}=2,41 L / h$

A vazão constante de etanol obtido corresponde a 2,41 L por hora. É possivel fazer esse calculo, pois a vazão se manteve constante durate o processo de destilação e o calculo utilizado é a relação entre volume em um determinado tempo.

A vazão do esperimento 1 não é possível determiná-la, pois não ocorreu a produção de álcool $94^{\circ} \mathrm{GL}$. Isso pode ser decorrente devido à má qualidade das leveduras.

\section{Rendimento da fermentação}

Não é possível calcular o rendimento da fermentação, pois na primeiro experimento não se obteve a produção de álcool $94{ }^{\circ} \mathrm{GL}$. E no segundo experimento não se obteve o teor alcoolico do vinho, pois o densímetro do laboratório é especifico para água e alcool.

\section{Conclusões}

A produção de bioetanol é possível de ser realizada em escala laboratorial desde que sejam mantidos os parâmetros dos fatores que afetam a fermentação, como a temperatura e o Brix.

No primeiro experimento não foi possível obter álcool $94{ }^{\circ} \mathrm{GL}$, por conta da má qualidade das leveduras, e no segundo experimento foi obtido álcool $94^{\circ} \mathrm{GL}$, por ser utilizado novas leveduras e pelo maior tempo de fermentação. 


\section{Referências}

SANTOS, R. E. R; SANTOS, I. A. Análise da viabilidade energética da produção de etanol em microdestilarias. Trabalho publicado no Congresso de Bioenergia, 2009.

PACHECO, T. F. Fermentação alcoólica com leveduras de características floculantes em reator tipo torre com escoamento ascendente.Dissertação (Mestrado em Engenharia Química), Universidade Federal de Uberlândia, 2010.

LIMA, L. R; MARCONDES, A. A. Álcool carburante: uma estratégia brasileira. Curitiba: Editora UFPR, 248p., 2002.

RIZZON, L.A; MENEQUZZO, J. Sistema de produção de destilado de vinho. Emprapa Uva e Vinho. Disponível em: < http://www.cnpuv.embrapa.br/publica/sprod/DestiladoVinho/destilacao.htm>. Acesso em: 19/10/2012.

GRUPO TCHÊ QUÍMICA. Produção de Etanol. Porto Alegre, RS. Disponível em: <http://www.deboni.he.com.br/etanol.pdf> Acesso em 19/10/2012.

VARELlA, C. A. A; BARROS, V. R; BAESSO, M. M. Mapeamento da variabilidade espacial do brix em cana-de-açúcar. Disponível em: <www.setor1.com.br/bebidas/vinhos/de_termbrix.htm> Acesso em 22/10/2012

COPPERCRAFTS. Destilação Simples. Disponível em: < http://www.coppercrafts.eu/index.php?option=com_content $\&$ view=article \&id=67\&Itemid=97 \&lang=pt $>$ Acesso em 22/10/2012. 